\title{
Examining Recruitment Practices for Servingness during COVID-19: Perspectives from Institutional Agents at an Emerging Hispanic-Serving Institution (HSI)
}

\author{
Natalia Deeb-Sossa ${ }^{1, *}$, Marcela G. Cuellar ${ }^{2}$, Mayra Nuñez Martinez ${ }^{2}$, Yadira Sanchez Nava ${ }^{3}$ \\ and Blas G. Guerrero ${ }^{4}$ \\ 1 Department of Chicana/o Studies, University of California, Davis, CA 95616, USA \\ 2 School of Education, University of California, Davis, CA 95616, USA; marcuellar@ucdavis.edu (M.G.C.); \\ manunez@ucdavis.edu (M.N.M.) \\ 3 Psychology and Chicana/o Studies Major, Education Minor, University of California, Davis, CA 95616, USA; \\ ysnava@ucdavis.edu \\ 4 Samuel Merritt University, Oakland, CA 94609, USA; bguerrero@samuelmerritt.edu \\ * Correspondence: ndeebsossa@ucdavis.edu
}

Citation: Deeb-Sossa, N.; Cuellar, M.G.; Nuñez Martinez, M.; Sanchez Nava, Y.; Guerrero, B.G. Examining Recruitment Practices for Servingness during COVID-19: Perspectives from Institutional Agents at an Emerging Hispanic-Serving Institution (HSI). Educ. Sci. 2021, 11, 454. https:// doi.org/10.3390/educsci11090454

Academic Editors: Sylvia Hurtado, Eleanor Dommett and Krystle Palma Cobian

Received: 13 July 2021

Accepted: 18 August 2021

Published: 24 August 2021

Publisher's Note: MDPI stays neutral with regard to jurisdictional claims in published maps and institutional affiliations.

Copyright: (c) 2021 by the authors. Licensee MDPI, Basel, Switzerland. This article is an open access article distributed under the terms and conditions of the Creative Commons Attribution (CC BY) license (https:// creativecommons.org/licenses/by/ $4.0 /)$.

\begin{abstract}
The COVID-19 pandemic hit in March 2020 as high school seniors were receiving their college admission notifications for fall. Many postsecondary institutions shifted outreach efforts to online formats. This qualitative study examines how virtual recruitment at an emerging HSI incorporates culturally responsive practices from the perspective of institutional agents (IAs) who were involved in these efforts. We also consider how IAs perceive the broader commitment of the institution to serve Latinx/a/o students. Our findings expose limitations in effectively recruiting Latinx/a/os in virtual formats due to the digital divide. The IAs identify ways in which the university was not equipped to overcome unreliable broadband access and technology. These agents maintain a critical lens to identify how the institution can expand capacity and ensure that the work of supporting Latinx/a/o students is a shared responsibility and not concentrated on a few staff. The findings further raise awareness of the continued language divide in disseminating information to families who do not speak English. Our study provides insights on how universities nationwide and across the world can transform recruitment practices to more intentionally support minoritized students and families as they make enrollment decisions into college.
\end{abstract}

Keywords: emerging Hispanic Serving Institutions (HSIs); culturally responsive recruitment practices; servingness; institutional agents; pandemic

\section{Introduction}

The COVID-19 pandemic affected all facets of life nationally and internationally. The shutdowns in the United States beginning in March 2020 occurred simultaneously as high school seniors were receiving their college admission notifications for fall 2020. Postsecondary institutions shifted any outreach and yield efforts targeting these prospective students to online formats. These recruitment practices generally convey college information and perceptibly influence students' enrollment decisions. As enrollment in selective universities increases the likelihood of degree completion among racially minoritized groups, including Latinx/a/o students [1], such culturally responsive recruitment efforts are especially critical at institutions that are among the most selective. In this paper we use the term Latinx/a/o, and in particular the use of the " $X$ " as a gender-neutral alternative to destabilize the gender binary that the Spanish language ascribes ("Latino" as male and "Latina" as female), while also embracing diversity by foregrounding the multiplicity of identities rendered invisible by umbrella terms $[2,3]$. In an effort to expand the inclusivity of the label even further, we follow those scholars who have taken to using Latinx/a/o [2]. 
Culturally responsive recruitment efforts are also important for many institutions, such as Hispanic-Serving Institutions (HSIs) that seek to actively challenge deep-rooted White supremacy and colonialism in higher education [4,5]. With a growing number of Latinx/a/o students pursuing higher education, more institutions are meeting the enrollment criterion to be designated as HSIs, defined by the federal government as enrolling $25 \%$ Latinx/a/o undergraduates. In 2019-20, HSIs represented $18 \%$ of all postsecondary institutions in the United States [6]. Institutions currently enrolling between 15 and 24\% Latinx/a/o undergraduates are described as emerging HSIs as these institutions are likely to attain HSI designation in the future [7]. HSI designation refers to an institution reaching the defined threshold of enrolled Latinx/a/o students, as defined through the Higher Education Act, of $25 \%$. Therefore, "the HSI designation is a racialized designation, meaning it is connected to and evolves from the racial and ethnic identities of the students" [8] (p. 2). HSIs are heterogeneous on a variety of institutional characteristics, such as size, type (e.g., 2-year and 4-year), and resources [9], as well as selectivity with a growing representation of research universities that are emerging HSIs [10]. Reflecting this broader trend, five of the nine undergraduate campuses in the University of California, the state's preeminent research postsecondary system, are HSIs, and three are emerging HSIs.

Although the federal government does not provide guidelines for HSIs on how to best support Latinx/a/o students, scholars propose a comprehensive framework on multiple dimensions of servingness, including institutional structures for serving, such as engagement with the Latinx/a/o community and culturally relevant curriculum and pedagogy [4]. Although the framework does not directly address recruitment practices targeting Latinx/a/o students and families, these efforts are central to an HSI identity. Recruitment practices reflect one of the first points of contact between an institution and prospective Latinx/a/o students. In order to foster Latinx/a/o student success, HSIs must engage in intentional recruitment and curricular strategies interweaving culture and identity [11]. Given the enrollment-based federal definition, intentional outreach and recruitment of Latinx/a/o communities are common activities among emerging HSIs as they strive to enact their HSI identity and attain the designation [7]. How recruitment efforts at HSIs and emerging HSIs are culturally responsive towards Latinx/a/o students and families remains underexplored, particularly from the perspective of individuals directly involved in these recruitment processes.

The purpose of this study is to examine how virtual recruitment at an emerging HSI incorporates culturally responsive practices. We examine these practices from the perspective of institutional agents (IAs), individuals who actively support student success on campus. Institutional agents possess significant practitioner knowledge on student success [12], including in advocating and supporting the success of minoritized college students at HSIs [13], making their critical perspectives on culturally responsive recruitment practices of the institution important to understand. Our study also considers how these institutional agents perceive the broader commitment of the institution to serve Latinx/a/o students. The study centers these perspectives during the COVID-19 pandemic, given that the onset of physical distancing in spring 2020 coincided with recruitment and yield activities encouraging prospective admits to enroll in the fall. Universities quickly shifted these activities, including those targeting Latinx/a/os, into a virtual format. Latinx/a/o communities, however, are amongst the most impacted by the pandemic. Understanding how institutional agents perceive institutional commitment to serving Latinx/a/o communities can provide insights on how universities in the nation and the world can serve minoritized students and transform recruitment practices to more intentionally support students and families as they make enrollment decisions and transition into college. This is critical, in the short run, to ensure equitable access to higher education for Latinx/a/o students, and in the long run, to ensure the economic and social mobility of these students, their families, and communities. 


\section{Literature Review}

The pandemic led to many college uncertainties for college-bound high school seniors that impacted their college plans, which included financial insecurity, whether to delay or defer their admission, and whether it was worth attending college remotely [14]. In 2020, many colleges and universities experienced drops in college enrollment, with larger disparities being observed for high schools that were low-income and with a high minoritized student population [15]. Given these COVID-19 uncertainties and concerns and large disparities in college enrollment across high schools, it is more pressing to understand how colleges and universities adapted their recruitment efforts to target minoritized students during COVID-19. A recent study, for example, examined recruitment efforts of diverse surgical residents during COVID-19 and argued for the importance of active programming that includes tailored virtual programming for candidates who are underrepresented in medicine [16]. This includes having other residents who may share identities with candidates being present at these virtual events and ensuring that candidates are able to understand the climate around diversity, equity, and inclusion (DEI) in their program [16]. While this study underscores the importance of centering DEI and being intentional in developing these virtual recruitment efforts, it is important to consider how different institutions adapted recruitment efforts given the sudden shift to online platforms, including Latinx/a/o students at emerging HSIs.

The recruitment of Latinx/a/o students has garnered attention from various practitioners and scholars [7,17-19]. Acknowledging that Latinx/a/o students are diverse, admission and recruitment representatives have argued that recruitment efforts should reflect this diversity [19]. This has included understanding the shifting demographics in the institution's service region [20] and developing materials that "adapt to the contexts of particular communities and students" [18] (p. 177). This has emphasized the need for intentional recruitment of Latinx/a/os that is based on culturally relevant approaches reflecting the values of this community and including the family as part of the decision process [17], especially at emerging HSIs and HSIs. While practitioners have identified several recruitment and outreach practices that target Latinx/a/o students and families, there is limited research that examines most of these culturally relevant practices at emerging HSIs.

Emerging HSIs have engaged in various activities to cultivate a sense of belonging in an effort to enhance Latinx/a/o enrollment, including creating opportunities for students to visit campus [7]. Fostering a sense of belonging and making students feel welcomed while visiting campus has been identified as an important practice in the recruitment of Latinx/a/o students [19]. Outreach from college faculty is another practice that may increase a sense of belonging and enrollment among Latinx/a/o students. Having faculty on campus that was welcoming and supportive played a role in several Latinx/a/o students' decision to attend HSIs [21]. Students attending HSIs and non-HSIs also emphasized being able to connect with college students to improve recruitment efforts, as this helped students know what to expect in their college application process [21]. Furthermore, diversity-related messaging in recruitment and outreach efforts is another important practice. Universities that successfully recruited Latinx/a/o students created web pages that included diverse images and provided links and information to access financial aid and how students could join multicultural organizations on campus [22].

Yet, for many Latinx/a/o students, going to college is a collective, family decision [19]. Thus, considering practices that engage families, such as using linguistically relevant material, is crucial in the outreach and recruitment efforts of Latinx/a/o students. Using bilingual strategies when targeting Latin $x / a / o$ families and communities has been essential to recruit Latinx/a/o students at emerging HSIs [7]. Latinx/a/o students at HSIs felt that providing information to parents that include academic support services available for students and financial aid was effective in engaging families [21]. Delivering information in a linguistically relevant way, especially for families whose primary language is not English, has been identified as an important practice in the successful recruitment of Latinx/a/o students [22]. Yet, only a few universities were found to translate their university webpages 
in Spanish, which limits the type of information available for Spanish-speaking parents, especially as many of these webpages included information on diversity, admissions, and multicultural organizations [22]. Others have further explored how vocabulary and concepts used in the college application process and higher education need to be translated in a way that is accessible for students and families and not assume prior knowledge [18]. These scholars highlighted the role of institutions in making recruitment and admissions information accessible to students and families to encourage applying and/or enrolling in college.

In addition, supporting Latinx/a/o families' sense of belonging on campus can build a personal connection between parents, the campus, and educators [23], which can enhance recruitment. Hosting on-campus family visits and providing multilingual (Spanish-language) orientations are recommended practices to enhance Latinx/a/o recruitment $[22,24]$. Although few studies have explored the effectiveness of engaging Latinx/a/o family as part of recruitment, a study in a Midwest university examined the impact of a Spanish language parent and family member orientation (PFMO) program, a culturally responsive approach that infuses familismo into its content [23]. Familismo is the importance of maintaining family relationships, relying on family for support, and considering family needs before one's own [23]. The PFMO program had a positive impact on parents' sense of belonging and personal connections to the staff [23]. Participants appreciated being able to connect with Latinx/a/o staff that embraced families' culture and addressed their doubts during this orientation, suggesting the utility of similar approaches with recruitment efforts. However, the PFMO mainly reflects an in-person, culturally, and linguistically responsive practice, which may or may not achieve similar results in online delivery.

Successful recruitment of Latinx/a/o students has included caring faculty, staff, and administration that served as sources of information for students and were willing to go beyond their job duties to support recruitment [22]. Institutional agents have been found to play a crucial role in providing information that may be missing or may not be understood in recruitment materials that may hinder access to higher education for Latinx/a/o students and families [18]. Subsequently, emerging HSIs have also engaged in hiring staff dedicated to Latinx/a/o recruitment [7]. The extent to which institutions and institutional agents transform recruitment practices to best support the Latinx/a/o community, however, remains underexplored.

While not centered on cultural responsiveness, a recent study explored how online programs at research universities implement strategies and practices to recruit students to online degree programs, given the growth of such programs in higher education [25]. The insights from this study seem instructive for recruitment at research universities during the COVID-19 pandemic, given the shift to virtual events for prospective admits for what ended up as primarily an online college experience in fall 2020. Administrators across four universities identified their target profile of prospective students and leveraged their institutions' brands to recruit students. While many of these programs initially outsourced recruitment to a third party, this was largely contingent on the stage of online program development. Institutions with well-established online programs relied more heavily on individuals within an institution to recruit students. Administrators further described a paradigm shift from passive admissions practices to those that were more high-touch and involved more personalized recruitment. While these insights highlight the importance of intentional online recruitment efforts, it is important to consider the challenges that may exist due to the digital divide present in many Latinx/a/o communities [26]. Given the COVID-19 pandemic, there is also a need to examine online recruitment efforts that target Latinx/a/o students at HSIs and emerging HSIs.

While recruitment efforts are important in achieving HSI status, scholars have emphasized the need for institutions to build capacity to better serve Latinx/a/o students when they arrive on campus. Latinx/a/o staff and faculty have been identified to play an important role in the success of Latinx/a/o students by serving as role models and mentors [27]. Thus, administrators have identified a need to increase the number of Lat- 
inx/a/o and culturally competent faculty and staff at emerging HSIs [27]. While this is an important practice that demonstrates institutions' commitment to better serve their Latinx/a/o population, other institutions have engaged in limited practices. For example, some HSIs and emerging HSIs continue to lack cultural programs and resources that target Latinx/a/o students [28]. This suggests a need to further explore institutions' commitment to better serve Latinx/a/o students in addition to examining the recruitment efforts utilized to increase Latinx/a/o enrollment.

\section{Conceptual Framework}

Our study is guided by the Multidimensional Conceptual Framework of Servingness in HSIs [4]. This framework posits that "servingness" is defined by multiple factors: (1) indicators of serving, which include student civic engagement, cultural validation, and interactions with peers, faculty, and staff who speak Spanish; (2) structures for serving, which comprise of culturally relevant content and teaching strategies, Latinx/a/o student engagement, and diversity of faculty, staff, and student body; and (3) external influences on serving, which encompass federal, state, and local legislation and role of community leaders [4] (p. 771). This study focuses on the first two elements of this model, indicators of serving and structures for serving, to understand the extent to which the institution is serving the Latinx/a/o community. Practically, this framework can help staff understand how their institutions can better serve their Latinx/a/o student population by identifying and transforming structures that may impede this [4]. Specifically, we focused on how institutional agents perceive the institution is serving Latinx/a/o students prior to students setting foot on campus through recruitment efforts.

This study contributes to the emerging literature that examines culturally responsive strategies that target minoritized students and families by highlighting institutional agents' perspectives on recruitment efforts and the broader institutional commitment to serving Latinx/a/o students. The study centers these perspectives during the COVID-19 pandemic, given that the onset of physical distancing in spring 2020 coincided with recruitment and yield activities encouraging prospective admits to enroll in the fall. Understanding how universities, such as emerging HSIs, outreached to Latinx/a/o student admits and families during the pandemic, a critical yield period, is important given the disparate impact of COVID-19 on this minoritized community. Given institutional agents' advocacy and support for minoritized students at HSIs [13], we examine how institutional agents perceived their virtual recruitment and yield efforts during the pandemic reflected "servingness" at an emerging HSI as well as the broader institutional commitment to serving support for Latinx/a/o students.

\section{Methods}

This study used qualitative approaches to examine the following research questions: (1) how did virtual recruitment efforts during the COVID-19 pandemic adopt culturally relevant approaches to reflect the values of Latinx/a/o admits and families? (2) How do institutional agents perceive the commitment of the institution to meet an HSI's mission? Qualitative approaches have been used to examine the importance of culturally responsive strategies for Latinx/a/o students and families [18,23]. Collecting data through one-onone interviews, qualitative researchers draw together the perspectives and experiences of individuals involved in complex social processes; in this endeavor, relationship building is key.

\subsection{Study Context}

In 2008, UC Davis set its long-term goal to become an HSI. UC Davis initiated a strategic plan to diversify the applicant pool from the state of California-the predominant source of applicants as a public research university. The strategic plan included the following activities to reach this goal: "(a) diversify the regional pool of applicants so that UC Davis attracts the top Chicanx/Latinx applicants from places such as the Imperial 
Valley and Salinas (Imperial Valley lies in the California counties of Imperial and Riverside and shares the international boundary between the US and Mexico, and Salinas is known as the 'Salad Bowl of the World' for its large agriculture industry and for being the most populous city Latinxs/as/os Northern California community) rather than drawing from the same pool as other institutions; (b) create a strong brand and reputation with high school counselors, superintendents, and other school influencers to encourage application and enrollment; (c) expand traditional events to include Chicanx/Latinx parents/caretakers and community influencers; (d) increase social capital with Chicanx/Latinx students through hosting visits that showcase UC Davis' intentional support mechanism and programs to guarantee their success and graduation; and (e) hire bilingual and bicultural admissions personnel who have, in turn, built trust and relationships with students' entire families and even their communities, to make UC Davis a university of choice" [29] (p. 71). Since then, the enrollment of Chicanx/Latinx students has steadily increased. The number of undergraduate Chicanx/Latinx students more than doubled from 3063 in 2008 to 6715 in 2018. This was a result of the intentional recruitment efforts set forth in the strategic plan of becoming an HSI [29].

Our examination of the 2019-2020 virtual recruitment efforts was facilitated by an existing partnership between the UC Davis' Strategic Diversity Recruitment Initiatives and Transfer Programs and faculty from the School of Education and the Chicana/o Studies Department. Through this partnership, we have examined the effectiveness of strategic efforts to increase Latinx/a/o enrollment and achieve HSI designation. These activities, which included using culturally humble and appropriate strategies, began in 2008 with the aim of supporting UC Davis' goal of becoming an HSI. One example of these recruitment strategies, the Salinas Experience, brought families from Salinas/Watsonville to campus for Decision Day. According to the 2019 HSI Task Force Report, "students who attended the event had a higher rate of submission of the Student Intent to Register (SIR) to UC Davis-90\% of the accepted students that attended the 2017 event submitted an SIR and several students turned down offers of admission from UCLA and UC Berkeley [the University of California, Los Angeles (UCLA) and University of California, Berkeley are the top two most selective universities in the University of California system]. The 90\% yield rate for this event greatly exceeds the yield rate for other similar events-usually between 64-72\%" [29] (p. 72).

Preliminary results from our pre-COVID evaluation of the Salinas Experience indicate that this intentional recruitment effort created a sense of community for students. About $44 \%$ of admitted Latinx/a/o and Chicanx/a/o students identified UC Davis' sense of community as an important determining factor in their decision to enroll at UC Davis. As a result of the pandemic, these recruitment and high yield strategies targeting Latinx/a/o prospective students had to shift online. The recruitment office developed at least seven webinars targeting Latinx/a/o admits and families during this time. The webinars included institutional agents and students discussing the following topics: housing, financial aid, study abroad programs, and student support programs (e.g., STEP). STEP, or Special Transitional Enrichment Program, provides academic and social support and resources for first-generation and low-income students transitioning into the university during their first 2 years [29]. Given the importance of information for Latinx/a/o families and a sense of community in the college choice process, we saw a strong need to gather realtime perspectives from institutional agents who participated in these online recruitment and outreach efforts. In this paper, we explore how 10 institutional agents perceived online recruitment strategies targeting Latinx/a/o students and incorporated culturally responsive practices in these strategies to ensure equitable access to selective institutions.

\subsection{Data Collection}

Once the project received Institutional Review Board (I.R.B.) approval, we emailed 17 Latinx/a/o institutional agents, namely, staff across various academic and student affairs departments, who were involved in planning or delivering the online webinars. Of 
these 17, 10 agreed to be interviewed. Thinking through all the stages of our data collection and analysis process [30], we acknowledge that interviews are "sites of power" [31] (p. 8) that reflect the potentiality of stories and serve as a "method of worlding" [31] (p. 8) and the process of "turning insight into instrument" [32] (p. xiii). Interviews allowed us as researchers and our participants to engage in new ways of understanding institutional agents' past recruitment experiences.

The participants represented a diverse cadre of Latinx/a/o professionals: six identified as female, seven were UC Davis alumni, and the number of years working at UC Davis ranged between 1 and 30 years. To protect the anonymity of our participants, we refer to them as "institutional agent" in our findings. All interviews were conducted in English, via zoom, and lasted approximately $1 \mathrm{~h}$ each. The interviews were conducted at the time that was most convenient for the institutional agent. Most institutional agents were working from home at this time due to the pandemic. The interviews were all conducted by the first author.

Through the interviews, we explored the intentional recruitment practices institutional agents engaged in outreach and recruit admitted Latinx/a/o students during the COVID-19 pandemic. We were interested in examining how institutional agents understood the importance of conveying a sense of belonging and sense of community, which are core goals of servingness, to Latinx/a/o students and families. We also examined what kind of challenges institutional agents encountered when conveying this messaging through online webinars. During the hour-long interview, institutional agents were asked what they already knew about performing online recruitment and yield work, what the main goal of the recruitment webinars was, the message they tried to convey about UC Davis in the few minutes they had during the webinars, why they tried to convey that message, and recommendations they had for admissions representatives and staff at other institutions that would like to reach out to their Latinx/a/o admits and families in a virtual platform over the next few years.

\subsection{The Positionality of the Five Authors}

Researchers in this project had existing partnerships and lasting collaborations with many of the institutional agents interviewed. In sites where these relationships exist, it is important to discuss how the researchers' own identities implicate how they interact with other participants, with researchers often balancing both outsider and insider status [33]. This is particularly true in sites where researchers have already developed relationships, as in this project where researchers had partnerships and lasting collaborations with many of the institutional agents. These partnerships and collaborations, we believe, as well as our reputation as scholar-activists, made the recruitment of institutional agents easier. For all these reasons, as scholars, we documented our own subjectivity throughout the research process, along with our decisions about data analysis and writing [31]. This included our decision not to include information about the institutional agents that would compromise their identity. We also decided to explicitly name the institution in our efforts to hold the institution accountable to better support its students and support the institution to fulfill its stated mandate of serving minoritized students.

Our research findings emerged amid the lived tensions between our various identities [34], as we "leveraged insider positioning" [33] (p. 261), [35] and built on existing relationships, within the university and between each other [36]. Four of the five authors identify as women, feminists, and come from working-class backgrounds. One of us identifies as a Latina originally from Colombia, one as a Latina originally from Mexico, one as a Chicano/Mexicano born in Mexico, and the rest of us were born in the United States. All of us are bilingual to varying degrees in English and Spanish and use both languages in our work.

In regard to this research, the deepest divides between us are professional: two are professors, one is a graduate student, one is an undergraduate, and one is a practitioner. This paper reflects our discussions about how to increase Latinx/a/o and Chicanx/a/o re- 
cruitment in culturally humble and appropriate ways. The paper also reflects our scholarly conversations [30] around how our university should cultivate a sense of belonging and sense of community for all students, but in particular for Chicanx/a/o and Latinx/a/o students. This includes discussing ways that the university can center these core goals of servingness in recruitment efforts [37]. As a result, this paper reflects genuine discussions among the authors about what the implications of this research are or should be.

\subsection{Data Analysis}

The first and fourth authors analyzed the data. We took a grounded theory approach [38] to examine the perspectives of institutional agents on UC Davis' recruitment efforts and commitment to becoming an HSI. The following themes emerged after a preliminary analysis of the interview transcripts: undervaluing of bilingual and bicultural staff, lack of commitment to Chicanx/a/o and Latinx/a/o students, and inequitable family engagement. After further reflection, we coded and organized our data into thematic "chunks" until reaching theoretical saturation [38]. This process highlighted the contrast between substantial support for HSI as an aspiration and the complex challenges involved in implementing culturally humble and appropriate recruitment of students and supporting them once they are on campus.

We then separated out data into two categories based on our conceptual framework: indicators of servingness and structures for serving. Our analysis of indicators of servingness was thematic, extracting key words and placing them into emerging categories of sense of community and sense of belonging. In thematically analyzing the structures for serving, we sorted these into four major categories: digital divide, linguistic divide, difficulties conveying an online sense of belonging and sense of community, and lack of commitment by the institution to serve Chicanx/a/o and Latinx/a/o students.

\section{Findings}

According to our interviews, the main goal of the webinars was to increase Latinx/a/o and Chican $\mathrm{x} / \mathrm{a}$ /o enrollment and achieve HSI status by attracting the top students from regions across California often ignored by other selective institutions. The institutional agents stated that the main messaging in these virtual outreach and recruitment events was for Latinx/a/o students to experience a sense of community and sense of belonging by conveying that UC Davis was a welcoming space. The interviews also exposed the limitations in effectively recruiting Latinx/a/o communities in virtual formats due to the existing digital divide among many Latinx/a/o communities. The institutional agents identified several ways in which the university was not equipped to overcome unreliable broadband access and technology. These agents also highlighted the limited capacity the university has in supporting Latinx/a/o students and how this responsibility is now centralized on a few staff. The institutional agents also raised awareness on the continued language divide in disseminating information to families who do not speak English or prefer communication in other languages, particularly Spanish.

In this section, we begin by illustrating the main goals and messaging in the webinars among institutional agents. We then give examples of how structures for serving shaped institutional agents' capacity to engage in online recruitment efforts and limited their ability to incorporate culturally responsive practices. Finally, we highlight institutional agents perspectives on how committed they believe leaders at UC Davis and their departments are to Chicanx/a/o and Latinx/a/o students as UC Davis aims to achieve HSI status.

\subsection{Fulfilling Core Goals of Servingness}

The main goal of the online recruitment webinars, which included information for students and families about various topics such as student support programs and financial aid, was to signal how UC Davis was a welcoming environment for Latinx/a/o students. According to the 10 institutional agents interviewed, this messaging was completed by communicating how Latinx/o/a students would experience a sense of community and 
sense of belonging once they were at UC Davis. For example, when asked what the main goal and message of the webinars was, three institutional agents responded that it was to show potential students that at UC Davis, "there is someone on campus that cares about them," "they are not going to be left alone, that they will always have someone here to help them," and "there are people here that really care about students and how you're doing".

Similarly, the majority of the institutional agents mentioned that the goal was to let potential students know that they belonged and had a community at UC Davis. The following quote is representative of this messaging:

Telling students that you belong in this place, regardless of who you are, where you come from, what you believe. You belong in this place. Serving these students is by showing the way students are performing but also the way students are integrating themselves or not integrating themselves into our community, do they see themselves as an Aggie (The UC Davis Aggies (also referred to as the Ags or Aggies) are the athletic teams that represent UC Davis. However, there was a push to make all students feel as part of the university and as part of the Aggie Pack by the One-UC Davis campaign) and not, and not necessarily, just as a student. (Institutional agent 4.)

This institutional agent asserted that the main goal of the webinars was communicated by acts, not only words, that showed Chicanx/a/o and Latinx/a/o students that they belonged. Likewise, another institutional agent also conveyed the importance of showing students that UC Davis is supportive. They noted:

To show students that they belong at Davis and to make them feel like they belong on campus, and so I think some of the ways in doing that are having a group of folks who identify as Latinx/a/o representing UC Davis and sharing their own experience of feeling of belonging, as well as expressing their interest in supporting the incoming students. So I think that's the goal and how we try to accomplish the goal. (Institutional agent 7.)

By sharing their own experience of belonging at UC Davis, this institutional agent identified the importance of having other individuals with shared identities such as being first-generation, Latinx/a/o, and bilingual, also sharing their experiences and finding mentors and role models to support students' success. This was a way of conveying to students how UC Davis was a welcoming space for Latinx/a/o students.

\subsection{Existing Structures Limit Culturally Responsive Practices}

Despite indicating to prospective students that UC Davis was a welcoming space for Latinx/a/o students, the existing structures for serving shaped institutional agents' capacity to effectively recruit online and limited their ability to incorporate culturally responsive practices. In this section, we consider the organizational structures that shaped institutional agents' capacity to address the digital and linguistic divides ever-present during COVID-19 and how these structures reflect a lack of commitment from the university to intentionally support Latinx/a/o students.

\subsubsection{Lack of Strategic Plan to Address Digital Divide}

The capacity to incorporate culturally responsive practices into recruitment efforts was severely limited by the COVID-19 pandemic - an external influence-given the onset of physical distancing in spring 2020. The recruitment office did not have a strategic and diversity plan in place to address the digital divide in an equitable and just way and the institution did not provide institutional agents with any support to address it.

Addressing the digital divide is critical as $79 \%$ of Latinx/a/o households in California had broadband subscriptions in 2019, compared to the statewide average of $84 \%$. Broadband subscription rates statewide were even lower among rural (73\%), low-income (76\%), and less-educated (80\%) households. In addition, in 2019, more than 1 in 10 Californians did not have a desktop, laptop, or other computing devices at home. Access was especially limited among low-income (22\%), rural (19\%), less-educated (19\%), and Latinx/a/o (20\%) households in California [26]. Given that the majority of student admits and those that 
enroll at UC Davis are from California [39], addressing the digital divide is crucial in recruitment efforts. In hindsight, institutional agents recognized that the digital divide disproportionately impacted some Latinx/a/o families, limiting the inclusivity of their recruitment efforts. To illustrate this, institutional agent 8 shared:

I think we could have done a better job of assessing the actual technology at home or connecting with the different players in different regions to know what technologies are available to students ... Are we being fair and equitable with what we're doing? We just went blind into this and kind of took it for granted.

As this quote reveals, institutional agents' capacity to meet minoritized students' needs was limited by not considering or intentionally addressing inequities that impact these students and their families. Failure of the university to strategize in advance, allocate resources, and consider Latinx/a/o households without broadband subscriptions and/or computer access at home when planning recruitment strategies will continue to limit the inclusivity, cultural responsiveness, and effectiveness of these efforts. According to institutional agent 5, if UC Davis wants to truly be a welcoming space, it must "think about ways to still engage those who are not tech savvy and what does that look like in this day in age". Servingness at HSIs and emerging HSIs requires recognizing the digital and technological needs of Latinx/a/o communities.

\subsubsection{Lack of Strategic Plan to Address Linguistic Divide and Engage Parents}

In addition to the digital divide, the institutional agents shared that they were not given the resources nor the capacity to address the linguistic divide, which limited the participation of non-English speaking parents in the webinars. The limited participation of these parents in webinars was in large part a result of the limited capacity to offer webinars in Spanish due to the limited number of bilingual staff in the recruitment office at the time. This issue was echoed by several institutional agents and stated most explicitly by institutional agent 5: "I feel like we could have done things in Spanish for so many of our monolingual Spanish-speaking families". For this institutional agent, the recruitment practices were not inclusive as they were unable to address the needs of non-English speaking parents, especially those of Spanish-speaking families. We are aware that not all Chicanxs' and Latinxs' parents speak Spanish. For example, the Mexican Government recognizes 63 Indigenous languages (e.g., Náhualt, Yucatec Maya, Mixteco). In South America, in addition to Spanish many speak Portuguese, Quechua, and Aymara. However, the university leaders and the institutional agents treated the Chicana/o/ $x$ and Latina/o/ $x$ as a monolithic population, resulting in assumptions, inaccurate generalizations, and stereotypes which, as a result, led them to be unprepared to address the needs of nonEnglish speaking parents. From the perspective of these institutional agents, this lack of servingness resulted from decisions made by UC Davis leaders, in particular their decision to reduce staffing at the recruitment office, limited budget for recruitment events, and placing little to no value on the work completed by the recruitment staff.

As mentioned above, admitted Latinx/a/o and Chicanx/a/o students have indicated that a sense of community and sense of belonging was a determining factor to enroll at UC Davis. Institutional agents felt unprepared and unsupported by the leaders at the university on how to convey a sense of community and a sense of belonging in online recruitment strategies targeting Latinx/a/o prospective students. Two institutional agents described how challenging it was to engage with students in a virtual format. Not being able to see students' faces or names limited their ability to form connections. The challenges raised by having to go virtual are explained by the following institutional agent:

I wish that we would have had a better way to connect with [monolingual Spanishspeaking] parents because we really didn't do that ... The best thing that I've ever had was parents thanking me. Just going out, having a meeting with the parent and reassuring them that ... Your son or daughter... Will be taken care of. We're going to 
support them and you know it's a safe place. And I'm just saying, how many parents never got that reassurance. (Institutional agent 8 .)

For this institutional agent, the limitation that the online recruitment venue posed to engaging with non-English speaking parents was further compounded by the language barrier and lack of webinars that were conducted to connect with non-English speaking parents. Given that in many Latinx/a/o households, the decision to go to college is a collective decision, and parents want to make sure that their daughter and/or son will be safe and supported-especially during COVID-19-these online recruitment efforts appeared to fall short in considering the family and trying to form a personal relationship with them in culturally responsive and appropriate ways.

\subsubsection{Lack of Commitment to Latinx/a/o and Chicanx/a/o Students by UC Davis}

While UC Davis has more than a decade-long history in the intentional recruitment of diverse Chicanx/a/o and Latinx/a/o students in its efforts to achieve HSI status, institutional agents perceived UC Davis' commitment to Latinx/a/o and Chicanx/a/o students as less than adequate at best, satisfactory at most. Overall, the institutional agents indicated that the institution per se was not committed. Institutional agent 1 commented: "They just think about bringing them in, and then they forget about them once they're here". From the perspective of institutional agent 7 , only a few staff were committed to Latinx/a/o and Chicanx/a/o students:

No, the institution is not committed. There's a difference between being an HSI-enrolling university and being an HSI-serving university, right? So the first being enrolling, we have these numbers we have met and the amount of Latinx/a/o students we have identified. Whereas an HSI serving is the part where we're not only saying that we have these accolades to be able to have a certain number of population represented as Latinx/a/o, we're showing it in not only the traditional metrics of education such as retention, raise persistent rates, graduation rates, those kinds of things, but we're also showing it in the way students are performing the way students are integrating themselves into our community.

This institutional agent captures the important distinction between enrolling or just admitting students, and servingness, which includes supporting and honoring students the way that they come.

All the institutional agents mentioned in their interviews that as a result of the lack of institutional commitment to Chicanx/a/o and Latinx/a/o students and the limited number of staff committed to these students once they are admitted, a lot of DEI work inequitably fell on their shoulders. Institutional agent 4 shared:

I know there's people on our campus that are doing good work and are showing up for Latinx/a/o students in ways that is way beyond anything that is required of them. And I know there's people that can be doing a lot more, a lot better.

For this institutional agent, there "were areas of excellence" at UC Davis. However, the problem was that "those areas of excellence typically land[ed] on the few staff committed to Latinxs students".

All 10 institutional agents interviewed agreed that a few staff were committed to the success of Chicanx/a/o and Latinx/a/o students. They explained that as a result, these staff performed an enormous amount of heavy lifting for the institution. Moreover, these institutional agents felt that this DEI work was often undervalued, unremunerated, and completed in addition to their multiple work responsibilities. In other words, these agents were performing duties beyond their assigned work responsibilities. This burden was described by institutional agent 8 :

Admissions office recruiters are the backbone and frontline for all recruitment efforts, yet this group is always underpaid and under-valued. In the last 12 months, the UC Davis Admissions Office has lost seven staff of color. How can the University expect to recruit 
students of color when there is no significant budget allocation for programming or the appropriate staffing to carry out the work? The institution will keep losing people of color because their work is not valued, the Latinx community is not valued. Additionally, some institutional leaders don't understand that the success we see today took time, took years of relationship building, trust, and hand shaking. I shook the hands of hundreds if not thousands of parents, I had to look at them in the eyes and say, 'we were going to take care of your daughter or son', and the University must fulfill that promise, because in the Latinx community, your 'palabra' (word or trust) is everything.

For this institutional agent, the limited budget allocated for recruitment efforts, the low wages paid to bilingual and bicultural staff performing recruitment and DEI work, and the lack of effort in retaining these staff reflected the priorities and values of the institution. This was echoed by other institutional agents who associated UC Davis's lack of commitment to Latinx/a/o students with their budgetary decisions and the lack of appreciation shown by UC Davis toward institutional agents performing culturally relevant recruitment and yield programs for Latinx/a/o students.

\section{Discussion}

Our study finds that institutional agents intentionally aimed to convey a sense of community in virtual recruitment efforts in order to enhance students' sense of belonging before arriving at college. Building on the importance of engagement in certain activities during college that foster membership and a sense of belonging [40], our study suggests that institutional agents are keenly aware of the importance of conveying a sense of community during recruitment efforts to inform Latinx/a/o students' college choice. Institutional agents underscore the significance of cultivating this sense of community in the virtual settings during the COVID-19 pandemic to introduce students to the campus, which contributes to the identification of indicators of servingness in recruitment efforts. Echoing the importance of high-touch recruitment for online programs at research universities [25] and positive messaging to prospective Latinx/a/o students at HSIs [11], our study extends these findings to recruiting Latinx/a/o students at emerging HSIs. Given the positive influence of campus visits on Latinx/a/o enrollment [17], which the pandemic severely limited as part of recruitment efforts, the significance of online recruitment approaches is magnified. Our findings overall suggest that engaging institutional agents may enhance online recruitment efforts to be more culturally responsive at HSIs and emerging HSIs.

Our findings also expose limitations in effectively recruiting Latinx/a/o communities in virtual formats due to the existing digital divide among many Latinx/a/o communities [26]. The institutional agents identify several ways in which the university was not equipped to overcome these particular infrastructure challenges in certain communities, including reliable broadband access and technology. While this may be partially explained by the short turnaround time institutions had to shift to online recruitment during the pandemic, these findings also point to existing challenges among HSIs with respect to technological access for students. For instance, HSIs offer limited digital access through their university websites for students with disabilities [41]. Similarly, in an examination of strategic plans among HSIs in Texas, with the exception of one institution, most do not articulate a strategic plan for institutional technology [42]. Our findings extend these findings to emerging HSIs and further suggest the need to address digital equity as a component of servingness in order to more intentionally support Latinx/a/o students and other minoritized students during recruitment and once students are enrolled.

The perceived shortcomings of structures for "serving" across an emerging HSI from the perspective of institutional agents is another contribution of our study. The agents in our study describe the need for institutional support in hiring more Latinx/a/o staff and financial investments in services to sustain recruitment efforts that aim to be culturally responsive, confirming prior studies indicating the importance of capacity-building for serving Latinx/a/o students at emerging HSIs [27]. The institutional agents in our study advocate for the success of Latinx/a/o students and developing a campus environment 
that supports these students, similar to other institutional agents at HSIs [13]. At the same, these agents maintain a critical lens to identify how the institution can expand capacity and ensure that the work of supporting Latinx/a/o students is a shared responsibility and not concentrated on a few staff. The findings also raise awareness on the continued language divide in disseminating information to Latinx/a/o families who do not speak English or prefer communication in other languages, such as Spanish. The lack of integrating Spanish, one of the primary languages among Latinx/a/os, at this emerging HSI, is similar to other HSIs [43].

\subsection{Implications}

Our study provides several recommendations for enhancing Latinx/a/o recruitment efforts, especially at HSIs and emerging HSIs. As initial points of contact with many minoritized communities, recruitment and yield efforts require innovative approaches that actively outreach and personalize connections to an institution. This requires a paradigm shift in traditional recruitment efforts to intentionally connect with Latinx/a/o students and families in a manner that cultivates a sense of community and an inviting welcome to an institution. Offering recruitment and yield events that target students and families can make evident how an institution supports Latinx/a/o students. These events should incorporate languages reflective of Latinx/a/o communities within an institution's service region, including Spanish, Portuguese, and Indigenous languages, to ensure families receive information in the most effective manner. Most of these events should be bilingual at the very least. We understand that this will be challenging due to staffing issues, even if students were included. Including institutional agents, such as Latinx/a/o staff and faculty, as well as current students in recruitment and yield activities, can further convey a sense of representation and community to prospective students and families. It is imperative that institutional staff and students are bilingual and bicultural and reflect the target audience. These institutional agents and students can, in turn, disseminate information and answer questions that may make an institution feel responsive to supporting students and families. Further, by engaging families in the recruitment process, institutions advance their branding and networking as these families will likely share their experiences with other families with their social networks.

Innovation should also occur in how admissions and financial aid notifications are delivered. In addition to emailing students, institutions should inform and maintain communication with parents as Latinx/a/o college enrollment decisions are often made collectively. Admissions notifications should also be sent to parents/caregivers when students provide an email at the time of application. However, it is important to note that not all Latinx/a/o parents/caregivers may regularly use email or may not feel comfortable using technology. In the several interviews conducted during COVID-19 with students and parents, it became apparent that some Latinx/a/o parents either did not have their own email address, or if they had one, the email account was managed by the student. This suggests that this line of communication with parents is limited or non-existent. Furthermore, some parents did not feel comfortable navigating Zoom during the interview without the student present to help them or did not have access to Zoom, so the interview was conducted via phone instead. This further suggests that access to technology is limited for Latinx/a/o parents and families. This will be explored and analyzed in more detail in future publications. Therefore, admissions officers should still mail hard copy admissions letters or packages to ensure students and families receive their admissions and financial aid information. As costs are likely a concern, institutions can mail admissions and financial aid postcards to arrive on or near the day as email notifications are sent. These notifications should also be translated into different languages reflecting the Latinx/a/o communities in the institution's service region.

As universities consider how to enhance recruitment and yield efforts, there may be a desire to transition to online recruitment fully or through hybrid models as a way to streamline services, reduce costs, and expand possible reach. However, institutions 
aiming to serve Latinx/a/o students and other minoritized student populations must remain mindful of the embedded inequities that may limit access for the most marginalized communities. Institutional leaders must consider the various challenges that may impact engagement in virtual outreach and recruitment activities. This includes providing adequate outreach and recruitment in rural settings where many Latinx/a/o students and families may not have access to reliable broadband or technology and/or updated computers and related technology. Many Latinx/a/o families cannot afford computers for each family member, and thus not every school or college again family member may be provided their own device. In addition to the barriers the digital and language divides pose, institutional leaders should also consider how the saturation of online sessions or email outreach can also impede the effectiveness of these touchpoints. Universities should thus continuously assess the effectiveness of these activities and the extent to which they are reaching the communities they are aiming to serve. Moreover, institutions should outline their technology goals in their strategic plans in order to ensure equitable access for Latinx/a/o communities remains at the fore in online settings.

At the institutional level, this research also has important implications for how organizations must create institutional support to sustain recruitment efforts that aim to be culturally responsive. Across emerging HSIs, institutional leaders must consider hiring culturally and linguistically competent Latinx/a/o staff with meaningful accompanying financial investments in capacity building for serving Latinx/a/o students [27].

\subsection{Research Implications}

The study, which identified several shortcomings for structures of "serving" from the perspective of institutional agents, highlights the need for more research in this area. The agents described the need for research on the impact of the different technologies on recruitment efforts. What technologies are more culturally competent? What technologies support more structures for "serving" across an emerging HSI?

Likewise, more research is needed to understand how the different recruitment efforts are experienced by Latinx/a/o students and their families. What are the experiences of students and their families in virtual recruitment efforts? What other recruitment efforts would be more culturally responsive for Latinx/a/o students at emerging HSIs? What other recruitment efforts would be more culturally responsive for their parents?

More research is needed that breaches the continued language divide in disseminating information to Latinx/a/o families who do not speak English or prefer communication in other languages, such as Spanish. How do emerging HSIs integrate Spanish, one of the primary languages among Latinx/a/os, in their recruitment efforts?

Latin $x / a / o s$ are the fastest-growing racially minoritized group that is entering postsecondary institutions. Due to the COVID-19 pandemic, postsecondary institutions shifted outreach and yield efforts targeting these prospective students to online formats. Culturally responsive recruitment efforts are critical for Latinx/a/o students and families as enrollment in selective 4-year universities increases the likelihood of these students attaining a bachelor's degree [1]. Given the findings in our preliminary pre-COVID research that indicated that creating a sense of community is one of the determining factors for admitted Latinx/a/o and Chicanx/a/o students to enroll at an emerging HSI, this study contributes to these institutions' success by understanding how to better convey a sense of community in the college choice process and effectively incorporate culturally responsive practices online.

Author Contributions: Conceptualization, N.D.-S.; methodology, N.D.-S.; formal analysis, N.D.-S. and Y.S.N.; literature review, M.G.C. and M.N.M.; writing-original draft preparation, N.D.-S., M.G.C., M.N.M., Y.S.N. and B.G.G.; writing—review and editing, N.D.-S., M.G.C., M.N.M., Y.S.N. and B.G.G. All authors have read and agreed to the published version of the manuscript.

Funding: This research received no external funding. 
Institutional Review Board Statement: We followed the guidelines of the UC Davis Institutional Review Board for all aspects of this study. The IRB ID \# is 1544041-2 approved on 3 August 2020.

Informed Consent Statement: Informed consent was obtained from all subjects involved in the study.

Data Availability Statement: Data are not available due to restrictions in privacy and ethical concerns.

Conflicts of Interest: The authors declare no conflict of interest.

\section{References}

1. Ruiz Alvarado, A.; Stewart-Ambo, T.; Hurtado, S. High school and college choice factors associated with high-achieving low-income students' college degree completion. Educ. Sci. 2020, 10, 153. [CrossRef]

2. Vidal-Ortiz, S.; Martínez, J. Latinx thoughts: Latinidad with an X. Lat. Stud. 2018, 16, 384-395. [CrossRef]

3. Rodríguez, R.T. X marks the spot. Cult. Dyn. 2017, 29, 202-213. [CrossRef]

4. Garcia, G.A.; Núñez, A.M.; Sansone, V.A. Toward a multidimensional conceptual framework for understanding "servingness" in Hispanic-serving institutions: A synthesis of the research. Rev. Educ. Res. 2019, 89, 745-784. [CrossRef]

5. Patton, L.D. Disrupting postsecondary prose: Toward a critical race theory of higher education. Urban Educ. 2016, 51, 315-342. [CrossRef]

6. Excelencia in Education. Hispanic-Serving Institutions (HSIs): 2019-20. 2021. Available online: https://www.edexcelencia.org/ research/series/hsi-2019-2020 (accessed on 27 June 2021).

7. Santiago, D.A.; Andrade, S.J. Emerging Hispanic-Serving Institutions (HSIs): Serving Latino Students. Excelencia in Education; 2010. Available online: https:/ / files.eric.ed.gov / fulltext/ED508203.pdf (accessed on 27 June 2021).

8. Garcia, G.A. Defining "servingness" at Hispanic-Serving Institutions (HSIs): Practical implications for HSI leaders. American Council on Education. 2019. Available online: https:/ / 1xfsu31b52d33idlp13twtos-wpengine.netdna-ssl.com/wp-content/uploads / 2019/12/Garcia-Essay-FINAL.pdf (accessed on 14 August 2021).

9. Núñez, A.M.; Crisp, G.; Elizondo, D. Mapping Hispanic-Serving Institutions: A typology of institutional diversity. J. High. Educ. 2016, 87, 55-83. [CrossRef]

10. Garcia, G.; Cuellar, M. Exploring curricular and cocurricular effects on civic engagement at emerging Hispanic-Serving Institutions. Teach. Coll. Rec. 2018, 120, 1-36.

11. Natividad, N.D. Lucha Libre and cultural icons: Identity formation for student success at HSIs. New Dir. High. Educ. 2015, 172, 91-101. [CrossRef]

12. Bensimon, E.M. The underestimated significance of practitioner knowledge in the scholarship on student success. Rev. High. Ed. 2007, 30, 441-469. [CrossRef]

13. Garcia, G.A.; Ramirez, J.J. Institutional agents at a Hispanic serving institution: Using social capital to empower students. Urban Educ. 2015, 53, 355-381. [CrossRef]

14. Reed, S.; Kurlaender, M.; Martorell, P.; Rury, D.; Hernandez Negrete, A.; Perry, P.; Moldoff, J.; Fuller, R. College Uncertainties: California High School Seniors in Spring 2020. California Student Aid Commission; 2020. Available online: https://www.csac.ca. gov/sites/main/files/file-attachments/csac_survey_report_20201217.pdf (accessed on 15 August 2021).

15. Causey, J.; Harnack-Eber, A.; Ryu, M.; Shapiro, D. High School Benchmarks: COVID-19 Special Analysis. Update \& Correction. National College Progression Rates. National Student Clearinghouse; 2021. Available online: https://files.eric.ed.gov / fulltext/ ED613158.pdf (accessed on 15 August 2021).

16. Gerull, K.M.; Enata, N.; Welbeck, A.N.; Aleem, A.W.; Klein, S.E. Striving for inclusive excellence in the recruitment of diverse surgical residents during COVID-19. Acad. Med. 2021, 96, 210-212. [CrossRef] [PubMed]

17. Gilroy, M. Tools for success in recruiting and retaining Hispanic students. Ed. Digest. 2010, 76, $20-23$.

18. Johnson, E.J.; Castrellon, T. Recoding discourses in higher education: Critical views on recruiting materials for Latin@ college students. J. Lat. Educ. 2014, 13, 166-180. [CrossRef]

19. Loveland, E. Creating a sense of community and belonging for Latinx students. J. Coll. Couns. 2018, 241, 44-49.

20. Torres, V.; Zerquera, D. Hispanic-serving institutions: Patterns, predictions, and implications for informing policy discussions. J. Hisp. High. Educ. 2012, 11, 259-278. [CrossRef]

21. Santiago, D.A. Choosing Hispanic Serving Institutions (HSIs): A Closer Look at Latino Students' College Choices. Excelencia in Education. 2007. Available online: https:/ / www.edexcelencia.org/research/issue-briefs/choosing-hispanic-serving-institutionshsis-closer-look-latino-students (accessed on 19 June 2021).

22. Montalvo, E. The recruitment and retention of Hispanic undergraduate students in public universities in the United States, 2000-2006. J. Hisp. High. Educ. 2012, 12, 237-255. [CrossRef]

23. Witkowsky, P.; Obregon, V.; Bruner, B.; Alanis, J. Connecting familismo and higher education: Influence of Spanish language PFMO programs of Latinx family involvement and sense of belonging. J. Hisp. High. Educ. 2018, 1-15. [CrossRef]

24. Smith, M.J. Four steps to a paradigm shift: Employing critical perspectives to improve outreach to low-SES African-American and Latino students and their parents. J. Coll. Admiss. 2008, 201, 17-23.

25. Ortagus, J.C.; Tanner, M.J. Going to college without going to campus: A case study of online student recruitment. Innov. High. Educ. 2019, 44, 53-67. [CrossRef] 
26. Public Policy Institute of California. California's Digital Divide. February 2021. Available online: https://www.ppic.org/ publication/californias-digital-divide/ (accessed on 21 June 2021).

27. Gooden, S.T.; Martin, K.J. Facilitating college success among emerging Hispanic Serving Institutions: Multiple perspectives yield commonly shared diversity goals. JPMSP 2014, 20, 1.

28. Corral, D.; Gasman, M.; Nguyen, T.H.; Samoyoa, A. An Examination of Existing and Emerging Hispanic Serving Institutions' Latino Initiatives and Culture. Center for Minority Serving Institutions, University of Pennsylvania, 2015. Available online: https: / / repository.upenn.edu/cgi/viewcontent.cgi?article=1387\&context=gse_pubs (accessed on 9 July 2021).

29. Aldana, R.; Reed, R. Investing in Rising Scholars and Serving the State of California: What It Means for UC Davis to Be a Hispanic Serving Institution. HSI Taskforce Report. March 2019. Available online: https://diversity.ucdavis.edu/sites/g/files/dgvnsk731 / files/inline-files/HSITaskForceReport_2019March29.pdf (accessed on 15 August 2021).

30. Jackson, A.Y.; Mazzei, L. Thinking with Theory in Qualitative Research: Viewing Data across Multiple Perspectives; Routledge: Oxfordshire, UK, 2011.

31. Freeman, E. Feminist theory and its use in qualitative research in education. In Oxford Research Encyclopedia of Education; Oxford University Press: Oxford, UK, 2019. [CrossRef]

32. Spivak, G.C. Readings; Seagull Books: Kolkata, India, 2014.

33. Aiello, J.; Nero, S.J. Discursive dances: Narratives of insider/outsider researcher tensions. J. Lang. Identity Educ. 2019, 18, 251-265. [CrossRef]

34. Duncan-Andrade, J.M.; Morrell, E. The Art of Critical Pedagogy: Possibilities for Moving from Theory to Practice in Urban Schools; Peter Lang Publishing, Inc.: New York, NY, USA, 2008.

35. Villenas, S. The colonizer/colonized Chicana ethnographer: Identity, marginalization, and co-optation in the field. Harv. Educ. Rev. 1996, 66, 711-732. [CrossRef]

36. Brown, K.D. Elevating the role of race in ethnographic research: Navigating race relations in the field. Ethnogr. Educ. 2011, 6, 97-111. [CrossRef]

37. Koro-Ljungberg, M.; Löytönen, T.; Tesar, M. Disrupting Data in Qualitative Inquiry: Entanglements with the Post-Critical and Post-Anthroposentric; Peter Lang-International Academic Publishers: Pieterlen, Switzerland, 2017.

38. Glaser, B.G.; Strauss, A.L. The Discovery of Grounded Theory: Strategies for Qualitative Research; Aldine: London, UK, 1967.

39. University of California. Undergraduate Admissions Summary. Available online: https://www.universityofcalifornia.edu/ infocenter/admissions-residency-and-ethnicity (accessed on 15 August 2021).

40. Hurtado, S.; Carter, D.F. Effects of college transition and perceptions of the campus racial climate on Latino college students' sense of belonging. Sociol. Educ. 1997, 70, 324-345. [CrossRef]

41. Taylor, Z.W.; Burnett, C.A. Hispanic-Serving Institutions and web accessibility: Digital equity for Hispanic students with disabilities in the 21st Century. J. Hisp. High. Educ. 2019. [CrossRef]

42. Flores, A.; Leal, D.R. Beyond enrollment and graduation: Examining strategic plans from Hispanic-Serving Institutions in Texas. J. Lat. Educ. 2020. [CrossRef]

43. Hallett, R.W.; Quiñones, F.M. The linguistic landscape of an urban Hispanic-Serving Institution in the United States. Soc. Semiot. 2021, 1-15. [CrossRef] 